\title{
SPECTROPHOTOMETRIC MEASUREMENT OF SOIL COLOR AND ITS RELATIONSHIP TO MOISTURE AND ORGANIC MATTER
}

\author{
J. A. Shields, E. A. Paul, R. J. St. Arnaud and W. K. Head \\ Saskatchewan Institute of Pedology, University of Saskatcbewan, Saskatoon, Saskatcbewan
}

Received April 8, 1968

\begin{abstract}
The color of soil samples taken from the Ap horizons of Chernozemic and Gray Wooded (Podzolic) soils was measured spectrophotometrically at moisture levels ranging from air-dryness to field capacity. The Munsell renotations "hue", "value" and "chroma" were related to the moisture content and the amount and nature of the soil organic matter. The addition of moisture to the Ap horizons from Chernozemic and Gray Wooded soils caused a significant decrease in value but had little effect on the hue and chroma. In Chernozemic soils the average decrease in value was 1.0 unit. This darkening in color occurred primarily in the moisture range between air-dryness and $18 \%$. The decrease in Gray Wooded soils averaged 1.7 units and it occurred throughout the moisture range from air-dryness to $30 \%$. The Gray Wooded soils were significantly higher in color value per unit of organic matter than were the Chernozemic soils. Differences were found in the ultraviolet reflectance spectra of these two kinds of soils and in the E4:E6 ratios of alkali extracts. The ratio of humic to fulvic acid and the amounts of $0.5 \mathrm{~N} \mathrm{NaOH}$ extractable humic acid also differed for the Gray Wooded and the Chernozemic soils.
\end{abstract}

\section{INTRODUCTION}

The increasing use of soil color as a definitive criterion in the classification of Chernozemic and Gray Wooded soils (11) must be considered from a practical standpoint. The ranges of definitive color criteria in the present Canadian system have become progressively narrower, to a point where it becomes questionable if the conventional method of visual measurement is precise enough to serve the purpose intended. Recently, it was reported that visual estimations of Munsell "value" by 12 observers for each of 20 samples showed variations ranging from 0.5 to 2.0 units, the average of which was 1.0 unit (17). It is apparent that the visual method of measuring crushed soil samples must be replaced by a more precise method.

The spectrophotometric color measurement of soil samples was first attempted more than three decades ago by Winters (21), who recognized that a standard method of sample preparation was required. He focused attention on the fact that mechanical grinding broke down aggregates whose interior color differed from that of the exterior. Carter (1) observed that the results of spectrophotometric measurement varied according to physical conditions as well as moisture content, and emphasized that individuals viewed colors differently due to physiological differences in the human eye. He also noted that the physical characteristics of the stimulus which produced the sensation were measured directly and exactly by the spectrophotometer.

Nickerson et al. (13) reported that the majority of their samples were measured through a glass cover and that only a few samples were "firmly packed" into a container and measured without a cover. They utilized a correction curve to adjust the measurements made through glass. The difficulties encountered due to measurement through glass were avoided by Shields et al. (17), who determined Munsell renotations on equipment which was

${ }^{1}$ Contribution No. R32, Saskatchewan Institute of Pedology.

Can. J. Soil Sci. Vol. 48, 271-280 (1968) 
purposely orientated to permit direct incidence of the light beam on the soil sample.

The relationship between the color and the nature of soil organic matter has been recognized for many years by a number of European workers. Springer (5) showed that the brown humic acids extracted from Podzolic soils were characterized by a lower percentage of carbon and a higher degree of dispersion than were the gray humic acids from Chernozem soils. Scheffer (16) proposed that the extinction coefficient (E) of humic acids was dependent on the degree of condensation of the aromatic nucleus, and indicated that the ratio of these coefficients measured at selected wavelengths was characteristic of the nature of the humic acid fraction. Kononova and Bel'chikova (7) reported E465:E665 ratios of 5.0 and 3-3.5 for Podzolic and Chernozemic soils respectively, and concluded that the degree of condensation of the aromatic nucleus of humic acid decreased as the ratio increased.

The composition of organic matter of the main soil groups of the U.S.S.R. has been characterized by the investigations of Tyurin and his co-workers $(5,6,7,20)$. They reported that the humus composition of various soils was characterized by the ratio of humic acids to fulvic acids. In Chernozems and Dark Chestnut soils, the ratio approached unity and often exceeded it; however, in Podzolic soils the ratio was less than unity. They also indicated that the humic acids of Podzolic soils extractable in $\mathrm{NaOH}$ were predominantly "free" or bonded to nonsilicate forms of sesquioxides, whereas the humic acids of Chernozem or Chestnut soils were mostly bonded to calcium.

The purpose of this study was to investigate the precision and accuracy of a technique developed for the preparation of soil samples for instrumental measurement of color when dry and moist. The spectrophotometric technique then was utilized to relate the color attributes to moisture content, certain organic fractions and the amount of organic carbon.

\section{Sample Selection}

\section{MATERIALS AND METHODS}

Bulk samples were taken from the Ap horizons of Brown, Dark Brown and Black, and Gray Wooded including Dark Gray Wooded soils in Saskatchewan $(8,9)$. The samples were of loam texture taken from profiles developed on medium-textured, moderately calcareous, undifferentiated glacial till. The classification of soils is based on the 1965 report of the National Soil Survey Committee (11). The Brown, Dark Brown and Black great groups belong to the Chernozemic order and the Dark Gray Wooded and Gray Wooded great groups occur within the Podzolic order.

\section{Spectropbotometric Technique}

A Bausch and Lomb model Spectronic 600 equipped with an ultraviolet reflectance attachment was used in this study. The instrument was mounted in a vertical position on the laboratory bench, permitting direct incidence of the light beam upon the granular soil sample placed at the measuring aperture.

Air-dry soil was crushed by hand, passed through a 35-mesh sieve and poured, slightly heaped, into a clean sample container (2) which was tapped firmly to ensure adequate packing and prevent subsequent settling. The sample 
was then levelled with the edge of a glass slide (held vertically) moved back and forth across the top of the container. The latter operation was repeated in several directions, accompanied, if necessary, by the addition of small amounts of the sample to fill the voids caused by previous levelling traverses. A flat plastic cover was then placed over the top of the container; the container was inverted, tapped firmly and returned to its original position. The plastic cover was then carefully removed and the container positioned beneath the measuring aperture for dry color measurement.

Subsequent to dry color measurement, the prepared samples were moistened by the addition of water. In order to minimize disruption of the sample surface, an atomizer was used to apply the water in the form of a very fine mist. Spraying was continued until the wetting front reached a depth of at least $1 \mathrm{~cm}$, to ensure that the sample surface was thoroughly moistened. Prior to color measurement, the samples were placed in an atmosphere approximating $100 \%$ relative humidity and allowed to equilibrate for 24 hours to field capacity. The high humidity of the environment served to prevent the surface particles of the sample from drying out during the equilibration period.

The color measurement of samples intermediate in moisture content between air-dryness and field capacity was taken after the moisture content was adjusted to the desired level in the pressure plate or pressure membrane. After 48 hours, the samples were removed from each apparatus, their reflectance was read and a representative subsample was taken for gravimetric moisture determinations.

The conversion of the reflectance measurements to trichromatic specifications $(X, Y, Z, x, y)$ was facilitated by the Ten Selected Ordinate method $(3,14)$. The results were then expressed in terms of C.I.E. color notations $(Y, x, y)$ which were subsequently converted to Munsell renotation "hue", "value" and "chroma" (12).

\section{Humus Composition and Nature of the Soil Organic Matter}

The humus composition was determined by the "quick method" developed by Kononova and Bel'chikova (7). This method involves extraction with a solution $0.1 \mathrm{M}$ in sodium pyrophosphate and $0.1 \mathrm{~N}$ in sodium hydroxide. The nature of the humic acid fraction, as given by the E465:E665 ratio, was determined by measuring the extinction coefficient (E) of an aliquot adjusted to a carbon concentration of $0.02 \mathrm{~g}$ carbon per liter. The humic acids which were "free" or bonded to nonsilicate forms of sesquioxides were extracted by a direct treatment with $0.5 \mathrm{~N} \mathrm{NaOH}$. The dry combustion method (15) was used to determine the organic carbon content of the soil samples and the organic matter fractions.

\section{Merits of Direct Incidence \\ RESULTS AND DISCUSSION}

Color measurements made on a number of Munsell standard papers by direct incidence (Table 1) are nearly identical with those published by the Munsell Color Company (10); however, serious discrepancies resulted when the color standards were measured through glass. This caused a decrease of up to 0.3 units of value and a range of \pm 0.5 units of hue from the standard data obtained by direct incidence. 
Table 1. Munsell renotations of standard Munsell papers measured by direct incidence and through glass

\begin{tabular}{|c|c|c|c|c|}
\hline \multirow{3}{*}{$\underset{\text { notation }}{\text { Book }}$} & \multirow{3}{*}{$\begin{array}{l}\text { Production } \\
\text { number }\end{array}$} & \multicolumn{3}{|c|}{ Munsell renotations } \\
\hline & & \multirow{2}{*}{$\frac{\text { G.E.R.S.* }}{\text { Direct incidence }}$} & \multicolumn{2}{|c|}{ Bausch and Lomb Spec. 600} \\
\hline & & & Direct incidence & Through glass \\
\hline $10 \mathrm{YR} 3 / 2$ & 6325 & $9.7 Y_{R} 2.98 / 1.9$ & $0.3 Y 3.0 / 2.0$ & $0.3 Y 2.7 / 2.1$ \\
\hline $10 \mathrm{YR} 4 / 2$ & 6913 & 10.0 YR $4.00 / 2.0$ & $9.8 \mathrm{YR} 4.0 / 2.0$ & $0.4 Y 3.7 / 2.0$ \\
\hline $10 \mathrm{YR} 5 / 2$ & 6538 & $0.3 Y 5.01 / 2.1$ & $0.6 Y 5.0 / 2.1$ & $0.8 Y 4.7 / 2.1$ \\
\hline $10 \mathrm{YR} 6 / 2$ & 6613 & 9.3 YR5 $.94 / 2.0$ & 9.2 YR5. $9 / 2.0$ & 9.6 YR5.7/2.0 \\
\hline $10 \mathrm{YR} 7 / 2$ & 6917 & 9.7 YR6.97/2.1 & 10.0 YR $7.0 / 2.0$ & 9.9 YR6.8/2.1 \\
\hline 10YR4/1 & 4496 & $10.0 \mathrm{YR} 4.02 / 1.2$ & $9.8 \mathrm{YR} 4.0 / 1.2$ & 9.6 YR3.8/1.3 \\
\hline $10 \mathrm{YR} 4 / 3$ & 4557 & $9.8 Y R 4.17 / 3.4$ & $9.8 Y R 4.2 / 3.4$ & 9.8 YR3 $9 / 3.5$ \\
\hline $10 \mathrm{YR} 4 / 4$ & $772 \mathrm{IT}$ & $10.0 Y R 4.16 / 4.1$ & $10.0 \mathrm{YR} 4.2 / 4.1$ & 9.6 YR3 $.9 / 4.2$ \\
\hline $7.5 \mathrm{YR} 5 / 6$ & 6965 & 7.7 YR5.05/6.3 & 7.7 YR5.1/6.3 & $7.9 Y R 4.8 / 6.2$ \\
\hline 2.5 YR5/4 & 4323 & 3.5 YR5 $22 / 4.2$ & 3.2YR5.2/4.2 & 3.0YR5.0/4.3 \\
\hline
\end{tabular}

*General Electric Recording Spectrophotometer utilized by the Munsell Color Company.

Table 2. Munsell renotations and organic carbon contents of Chernozemic and Gray Wooded Ap horizons

\begin{tabular}{|c|c|c|c|c|c|c|c|c|}
\hline \multirow[b]{2}{*}{ Great group } & \multirow{2}{*}{$\begin{array}{l}\text { Sample } \\
\text { number }\end{array}$} & \multicolumn{2}{|c|}{$\begin{array}{l}\text { Munsell } \\
\text { renotation* }\end{array}$} & \multirow{2}{*}{$\frac{\left\{\frac{\text { dry }}{\text { moist }}\right\}}{\text { Chroma }}$} & \multicolumn{2}{|c|}{$\begin{array}{l}\text { Standard } \\
\text { deviation }\end{array}$} & \multirow{2}{*}{$\frac{\left\{\frac{\text { dry }}{\text { moist }}\right\}}{\text { Chroma }}$} & \multirow{2}{*}{$\stackrel{\%}{\%}$} \\
\hline & & Hue & Value & & Hue & Value & & \\
\hline \multicolumn{9}{|l|}{ Chernozemic soils } \\
\hline Brown & 18 & $1.2 \mathrm{Y}$ & 4.4 & 2.5 & 0.18 & 0.03 & 0.06 & 1.36 \\
\hline \multirow{2}{*}{ Brown } & 136 & $\begin{array}{l}0.9 \mathrm{Y} \\
0.7 \mathrm{Y}\end{array}$ & $\begin{array}{l}3.3 \\
4.3\end{array}$ & $\begin{array}{l}2.6 \\
2.6\end{array}$ & $\begin{array}{l}0.20 \\
0.13\end{array}$ & $\begin{array}{l}0.10 \\
0.09\end{array}$ & $\begin{array}{l}0.08 \\
0.08\end{array}$ & \\
\hline & & $0.4 \mathrm{Y}$ & 3.1 & 2.6 & 0.24 & 0.09 & 0.12 & \\
\hline \multirow[t]{2}{*}{ Brown } & 139 & $1.5 \mathrm{Y}$ & 4.7 & 2.6 & 0.17 & 0.05 & 0.07 & 1.01 \\
\hline & & $1.4 \mathrm{Y}$ & 3.6 & 2.5 & 0.18 & 0.05 & 0.05 & \\
\hline \multirow[t]{2}{*}{ Dark Brown } & 169 & $0.8 \mathrm{Y}$ & 3.7 & 1.9 & 0.18 & 0.04 & 0.05 & 2.19 \\
\hline & 170 & $0.7 \mathrm{Y}$ & 2.6 & 1.9 & 0.08 & 0.08 & 0.04 & \\
\hline Dark Brown & 170 & 1.1Y & 4.0 & 1.9 & 0.14 & 0.04 & 0.03 & 1.92 \\
\hline \multirow[t]{2}{*}{ Dark Brown } & 174 & $1.1 \mathrm{Y}$ & 4.0 & 2.1 & 0.17 & 0.05 & 0.03 & 2.10 \\
\hline & & $1.1 \mathrm{Y}$ & 2.8 & 2.0 & 0.20 & 0.11 & 0.11 & \\
\hline \multirow[t]{2}{*}{ Black } & 148 & $0.4 \mathrm{Y}$ & 3.4 & 1.7 & 0.14 & 0.06 & 0.03 & 2.78 \\
\hline & & $10.0 \mathrm{YR}$ & 2.4 & 1.6 & 0.23 & 0.05 & 0.04 & \\
\hline \multirow[t]{2}{*}{ Black } & 144 & $0.8 \mathrm{Y}$ & 3.0 & 1.1 & 0.21 & 0.03 & 0.03 & 4.56 \\
\hline & 146 & $0.6 \mathrm{Y}$ & 2.1 & 1. 0 & 0.48 & 0.08 & 0.06 & \\
\hline Black & 140 & $0.7 Y$ & 2.8 & 1.2 & 0.20 & $\begin{array}{l}0.04 \\
0.07\end{array}$ & $\begin{array}{l}0.03 \\
0.05\end{array}$ & 0.02 \\
\hline \multicolumn{9}{|c|}{ Gray Wooded soils } \\
\hline Dark Gray & 149 & $0.5 \mathrm{Y}$ & 4.6 & 1.9 & 0.19 & 0.04 & 0.05 & 2.62 \\
\hline Wooded & & $0.1 \mathrm{Y}$ & 3.0 & 1.8 & 0.15 & 0.08 & 0.05 & \\
\hline Dark Gray & 154 & $0.3 \mathrm{Y}$ & 5.0 & 2.1 & 0.11 & 0.05 & 0.0 & 2.03 \\
\hline Wooded & & $9.9 \mathrm{YR}$ & 3.5 & 2.0 & 0.11 & 0.08 & 0.05 & \\
\hline Dark Gray & 147 & $0.6 Y$ & 5.2 & 2.3 & 0.14 & 0.06 & 0.06 & 1.60 \\
\hline Wooded & & $0.4 Y$ & 3.6 & 1.9 & 0.19 & 0.10 & 0.08 & \\
\hline \multirow[t]{2}{*}{ Gray Wooded } & 159 & $0.7 \mathrm{Y}$ & 5.8 & 1.7 & 0.23 & 0.05 & 0.05 & 1.27 \\
\hline & & $0.5 \mathrm{Y}$ & 3.9 & 1.7 & 0.28 & 0.14 & 0.08 & \\
\hline \multirow[t]{2}{*}{ Gray Wooded } & 160 & $1.0 \mathrm{Y}$ & 5.7 & 1.7 & 0.11 & 0.05 & 0.0 & 1.70 \\
\hline & $16 ?$ & $0.3 \mathrm{Y}$ & 3.8 & 1.5 & 0.21 & 0.14 & 0.06 & \\
\hline Gray Wooded & 102 & $1.1 \mathrm{Y}$ & 5.6 & 1.5 & 0.20 & 0.05 & 0.0 & 1.90 \\
\hline \multirow{2}{*}{ Gray Wooded } & $117-1$ & $1.0 \mathrm{Y}$ & 5.5 & $\begin{array}{l}1.4 \\
2.0\end{array}$ & 0.13 & 0.05 & 0.05 & 1.35 \\
\hline & & $0.8 Y$ & 4.0 & 1.7 & 0.17 & 0.14 & 0.06 & \\
\hline
\end{tabular}

*Average of 12 separate preparations. 
Soil sample colors measured through glass are subject to similar errors, particularly in the case of moist soil measurements when air-glass and glasswater interfaces are frequently encountered. Complicated correction factors worked out by various workers to compensate for the effects of glass have not proven satisfactory (4).

\section{Spectrophotometric Technique}

The Munsell renotations for each of 10 individual measurements provided an index of the precision of the spectrophotometric technique. The standard deviations (Table 2) for hue, value and chroma when measured dry were less than $0.5,0.1$ and 0.1 units, respectively. Similarly, those determined on the results of measurements for soils moistened to field capacity were less than 0.5 , 0.2 and 0.1 units, respectively. It is apparent that the precision of these measurements was superior to that of measurements determined visually (17).

\section{Effect of Moisture on Soil Color}

Moisture had no significant effect on the hue or chroma of Chernozemic and Gray Wooded soils (Table 2). However, the addition of moisture caused the value of Gray Wooded soils to decrease by 1.5 to 2.0 units, compared with a decrease of only 1.1 units in the Chernozemic soils. These results differ from the visual measurements reported by the U.S. Department of Agriculture (18), which indicated that moist soils are commonly 0.5 to 0.3 units lower in value and may change from 0.5 to 2.0 units in chroma, but seldom differ in hue. The results of earlier spectrophotometric measurements (17) showed that the value of Gray Wooded soils decreased up to 2.7 units on moistening; however, this greater decrease was probably due to variations in sample preparation used prior to this investigation.

The characterization of the color changes occurring between air-dryness and field capacity necessitated the measurement of the color of samples adjusted to various intermediate moisture contents. The curves iliustrating the moisture content-value relationships for the Chernozemic soils (Fig. 1) indicate that the decrease in value occurred primarily between air-dryness and $18 \%$ moisture, with no significant change between 20 and $40 \%$. In contrast, the value of the Orthic Gray Wooded sample (Fig. 2) decreased in a curvilinear form from air-dryness to over 30\% moisture. The work of Souza Coelho and Audi (19) indicated that there was little change in the color of soils at moisture contents between 12 and $40 \%$. This discrepancy is very likely a reflection of differences in soil and the techniques used to measure color at particular moisture contents.

\section{Color-Organic Matter Relationships}

The relationship between organic matter and color is best expressed by plotting the organic carbon content as a function of Munsell renotation value. Although there is no direct linear relationship between the two, it is apparent that the value decreased as the carbon content increased (Fig. 3). This trend is particularly striking among the Chernozemic samples, which ranged from $1 \%$ carbon with a value of 4.7 to $6.0 \%$ carbon with a value of 2.8 . The value of the lighter-colored Gray Wooded soils also decreased as the carbon content increased; however, the carbon content of these soils was higher than expected 

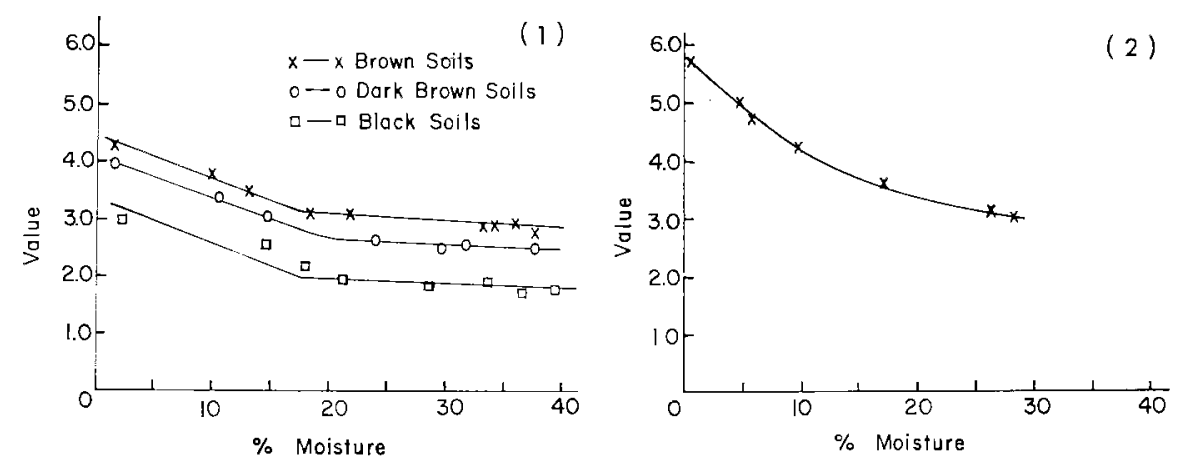

Fig. 1. The relationship between Munsell renotation value and percent moisture by weight of Chernozemic soils.

Fig. 2. The relationship between Munsell renotation value and percent moisture by weight of a Gray Wooded soil.

in consideration of their high values. The fact that a Chernozemic and a Gray Wooded sample may differ in value by nearly one unit but still have approximately the same carbon content, suggests that the organic matter of these soils is different in nature. This difference could be due to the nature of the organic matter, the nature of the association between the organic and inorganic constituents, or the nature of the mineral matter. As indicated previously, these soils were all developed on medium-textured, moderately calcareous, undifferentiated glacial till. The differences in the relationship between the organic carbon and value for Chernozemic and Gray Wooded soils are therefore deemed largely due to the nature of the organic matter.

The E465:E665 ratios (Table 3) of the humic acid solutions extracted from selected samples tend to be segregated into two distinct groups. The ratios of the Chernozemic samples were relatively narrow (3.6 to 4.2 ). This has been attributed to a relatively high degree of condensation of the aromatic

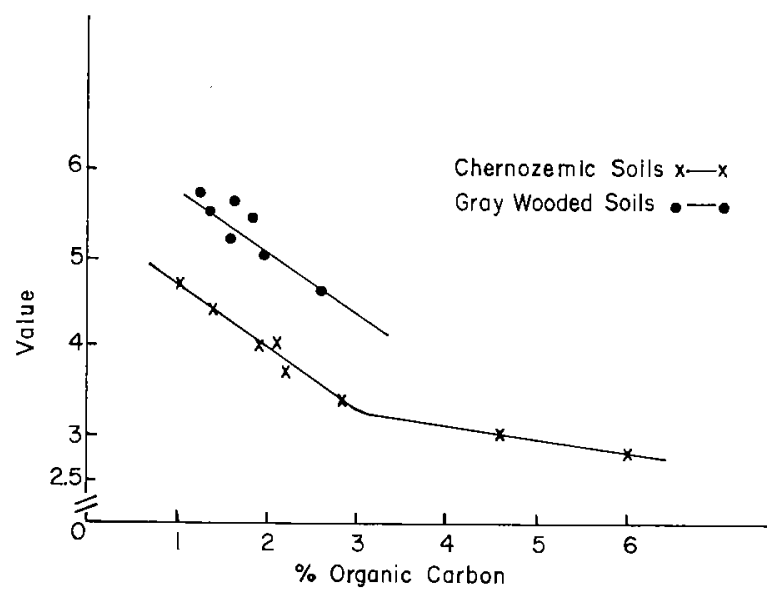

FIG. 3. The relationship between Munsell renotation value and organic carbon content of air-dry soils. 
nucleus, compared with the wider ratios (5.1 to 5.7) of the Gray Wooded samples (7).

The difference in the nature of the organic matter is also illustrated by the distinct break in the line relating the E4:E6 ratios and renotation values of Chernozemic and Gray Wooded samples (Fig. 4). The relative lightness or darkness of a sample as denoted by value is measured by integrating the absorbance of light at selected wavelengths within the visible range. Consequently, it is not surprising that value is related to the relative absorbance of light at two wavelengths (E4:E6 ratio), suggesting that value alone may reflect the nature of soil organic matter. The determination of value is based on known psychophysical principles; therefore, this measurement could prove more useful in studying the nature of soil organic matter than an empirical ratio based on only two wavelengths.

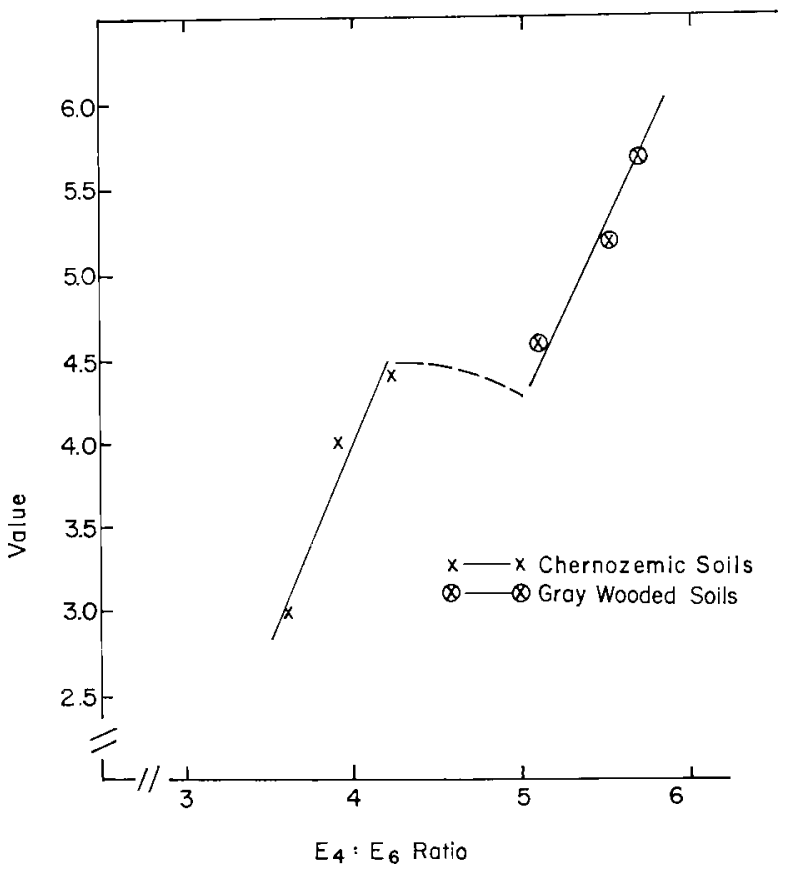

Fig, 4. Munsell renotation value (when dry) plotted as a function of the E4:E6 ratio.

Differences in the nature of the organic matter present were also demonstrated by selective light absorbance in the non-visible, ultraviolet portion of the spectrum (Fig. 5). The curves from Chernozemic (No. 170) and Gray Wooded (No. 160) soils containing approximately the same amount of organic carbon differ markedly. The reflectance readings for the Gray Wooded soils were not only significantly higher throughout the measured range of wavelengths, but also showed a greater difference between readings at the points of minimum and maximum reflectance. The point of minimum reflectance in the Podzolic sample occurred at $245 \mathrm{~m} \mu$, whereas the minimum reading for the Chernozemic sample occurred at $255 \mathrm{~m} u$. 


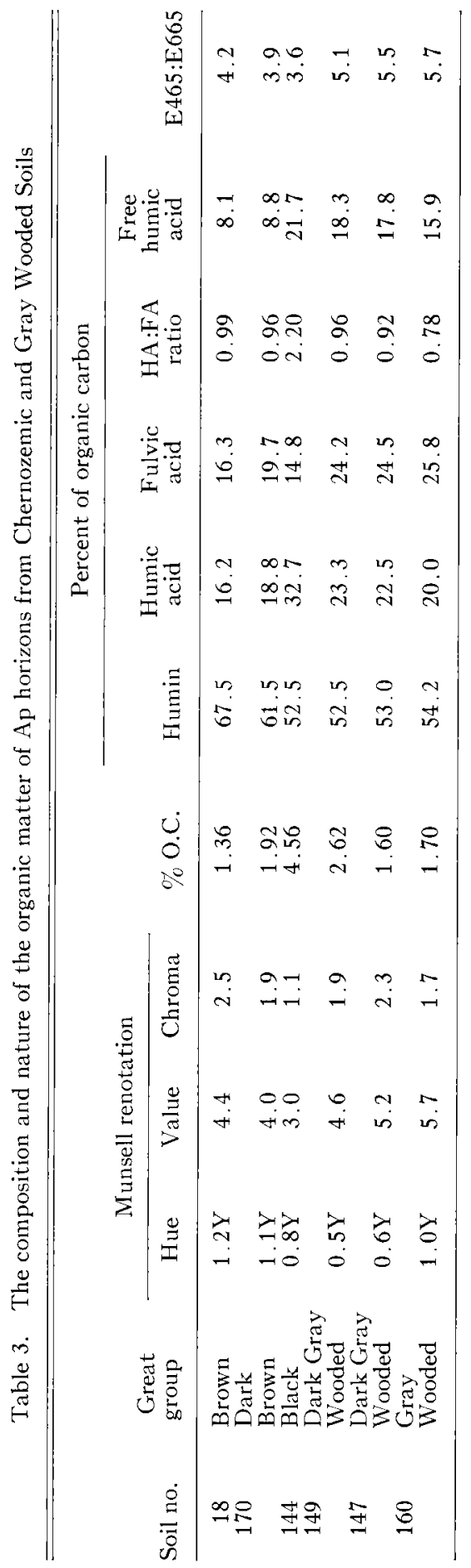




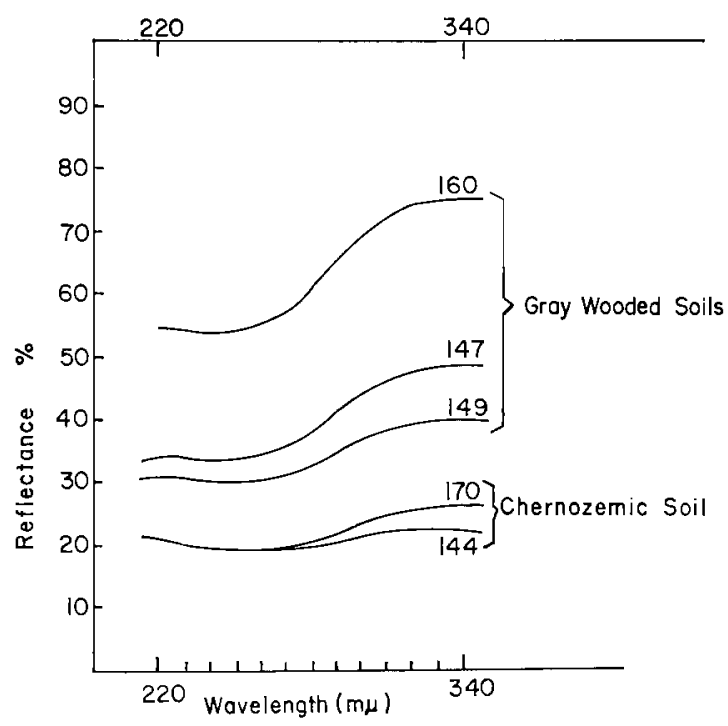

FIG. 5. Ultraviolet reflectance spectra (20\% full scale) of Ap horizons from Chernozemic and Gray Wooded soils.

On the basis of the extractable organic matter fraction, no single criterion could be used consistently to differentiate the organic matter of one great group from that of another (Table 3). However, on the basis of chemical composition, humic acid:fulvic acid ratio and the optical properties of the humic acid fraction, considered collectively, the samples could be segregated among three groups. The Brown and Dark Brown Chernozemic soils are characterized by a relatively small amount of humic acids which are nearly equal to the fulvic acids, resulting in a ratio approaching unity. In contrast, the Black Chernozemic soil has a relatively high amount of humic acids and a ratio of humic to fulvic acids greater than 2. Gray Wooded soils are characterized by higher amounts of fulvic acids, which exceed the humic acids. Nearly $80 \%$ of the total humic acids of this group were extractable with $0.5 \mathrm{~N} \mathrm{NaOH}$, compared with a relatively lower amount extracted from the Chernozemic soils. The ratio of the extinction coefficients (E465:E665) determined on the humic acids extracted from Gray Wooded soils were significantly higher (5.1 to 5.7 ) than those extracted from the Chernozemic samples (3.6 to 4.2).

The organic matter characteristic of the Gray Wooded soils is similar to that of cultivated sod-Podzolic soils described by Kononova (5), with the exception that the humin percentage is lower in the latter soils. The composition and nature of the organic matter from the Black Chernozemic soil closely resemble those of the "ordinary Chernozem" of the U.S.S.R. However, the latter have a lower amount of "free humic acids" extractable with $0.5 \mathrm{~N}$ $\mathrm{NaOH}$. The Brown and Dark Brown Chernozemic samples appear to be intermediate between those of the cultivated Dark Chestnut and the Sierozem soils of the U.S.S.R. 


\section{CONCLUSIONS}

The use of a glass cover over diffusing surfaces gave rise to errors in their color measurement, indicating that measurement through glass should be avoided whenever possible. The spectrophotometric technique descibed herein facilitated measurement of the color of soils at field capacity with a precision in the same order as that obtained for dry samples. It also provided an opportunity to measure the color of samples adjusted to different moisture levels. The change in color accompanying the addition of moisture to Chernozemic soils was characteristically different from that occurring in the Gray Wooded samples. These differences were observed in comparing their colors not only when dry and at field capacity, but for intermediate moisture contents as well.

The relationship between soil color and the organic carbon content of Chernozemic soils differed significantly from that of Gray Wooded soils. The differences were associated with differences in $\mathrm{E} 4: \mathrm{E} 6$ ratios, humic to fulvic acid ratios and the percent of $\mathrm{NaOH}$-extractable humic acids.

\section{ACKNOWLEDGEMENTS}

The technical assistance of Mrs. J. Burns is gratefully acknowledged.

\section{REFERENCES}

1. Carter, W. T. 1931. Color analysis with spectrophotometer. Amer. Soil Surv. Assoc. Bull. 12, 169-170.

2. HeAD, W. K. 1967. Spectroreflectance measurement of moist-soil color. B.S.A. Thesis, Dep. Soil Sci., Univ. Saskatchewan, Saskatoon.

3. Judd, D. B. 1952. Color in business, science, and industry. John Wiley and Sons, Inc., $\mathrm{X}, \mathrm{Y}$.

4. Jind, D. B. and Gibsox, K. S. 1936. Note on the effect of a cover glass in reflectance measurements. J. Res. Nat. Bur. Stand. 16, 261-264.

5. Kononova, M. M. 1961. Soil organic matter. Its nature, its role in soil formation and in soil fertility. Pergamon Press, London.

6. Kononova, M. M. and Bel'Chikova, N. P. 1960. Investigations of the nature of soil humic substances by fractionation methods. Pochvovedenie 1149-1155.

7. Kovonova, M. M. and Bel'chikova, N. P. 1961. Quick methods of determining humus composition of humus soils. Pochvovedenie 1112-1121.

8. Mrtchell, J., Moss, H. C. and Claytox, J. S. 1944. Sask. Soil Surv. Rep. No. 12

9. Mitchell, J., Moss, H. C. and Clayton, J. S. 1950. Sask. Soil Surv. Rep. No. 13.

10. Munselt Color Co., Incorp. 1950. Munsell soil color charts, special form for use by soil scientists, geologists and archaeologists. Baltimore, Md.

11. National Soll Survey Committee (Canada). 1967. Report of 6th Nat. Meet., Quebec, 1965, Can. Dep. Agr., Ottawa.

12. Newhald, S., Nickerson, D. and Judd, D. B. 1943. Final report of the O.S.A. subcommittee on the spacing of the Munsell colors. J. Opt. Soc. Amer. 30, 575-586.

13. Nickerson, D., Kelly, K. L. and Stultz, K. F. 1945. Color of soils. J. Opt. Soc. Amer. 35, 297-300.

14. Optical Society of America, Committee on Colorimetry. 1953. The science of color. T. Y. Crowell Co., New York.

15. St. Arnaud, R. J. 1956. Manual of laboratory methods. Dep. Soil Sci., Univ. Saskatchewan. pp. 32-36.

16. Scheffer, F. 1954. Neuere Erkenntnisse in der Humusforschung. Trans. 5th. Int. Congr. Soil Sci., Leopoldville, 1, 208-228.

17. Shields, J. A., St. Arnatd, R. J., Paur, E. A. and Clayton, J. S. 1966. Measurement of soil color. Can. J. Soil Sci. 46, 83-90.

18. Soll Survey Staff. 1951. Soil survey manual. U.S. Dep. Agr. Handb. 18.

19. Souza Coelho, A. G. and Audr, R. 1964. Color in relation to moisture level in some soil series. Bragantia 23, 117-128.

20. Tyurin, I. V. 1953. Methods of analysis for the comparative study of soil humus composition. Chem. Abstr. 47, 5597.

21. Winters, E. 1930. The measurement of soil color. Amer. Soil Surv. Assoc. Bull. 11, 34-37. 